\title{
Fully Endoscopic Interlaminar Detethering of Spinal Cord in Tethered Cord Syndrome: A Case Report and Technical Description
}

\author{
Mehmet Sabri Gürbüz" Salih Aydín ${ }^{1}$, Deniz Bozdoğan² \\ ${ }^{I}$ Department of Neurosurgery, Neurosurgery Clinic, Emsey Hospital, Ïstanbul, \\ ${ }^{2}$ Department of Anesthesiology, Anesthesiology Clinic, Emsey Hospital, Ïstanbul, Turkey
}

\begin{abstract}
A 19-year-old man presented with long lasting significant back and bilateral leg pain, and hypoesthesia on the lateral side of both his thighs for which he had undergone several courses of medication and bouts of physical therapy treatment. His urodynamic parameters were normal and lumbar magnetic resonance imaging (MRI) revealed a low-lying conus at the L2-3 level with a thickened fatty filum, and he was diagnosed as having tethered cord syndrome (TCS). The patient underwent a fully endoscopic detethering through an interlaminar approach with intraoperative neurophysiological monitoring. The thickened filum terminale was located and then the filum was coagulated and cut. The patient showed a significant improvement in his preoperative symptoms, and reported no problems at 2-year follow-up. Detethering of the spinal cord in tethered cord syndrome using a fully endoscopic interlaminar approach provides the advantages of minimal damage to tissues, less postoperative discomfort, early postoperative recovery, and a shorter hospitalization.
\end{abstract}

Key Words: Endoscopic interlaminar technique $\cdot$ Tethered cord syndrome $\cdot$ Endoscopic detethering

\section{INTRODUCTION}

The essential mechanical factor of cord tethering is that any of the inelastic structures fastening the caudal end of the spinal cord produce traction effects on the lumbosacral $\operatorname{cord}^{32,35)}$. Most of the conditions resulting in tethered cord syndrome (TCS) are congenital. This syndrome may be closely associated with spina bifida, tight filum terminale, lipomeningomyelocele, split cord malformations, dermal sinus tracts, dermoids and cystoceles. The acquired causes of TCS are as a result of spinal injury or following surgery for myelomeningocele, or any intradural surgical intervention relevant to the spinal cord $^{8,27,299}$.

Open surgical detethering of the spinal cord is currently the gold standard and with reported satisfactory postoperative results $^{1,9,13,16,31)}$. However, some patients develop retethering due to scar formation which may require additional surgery ${ }^{24)}$. Recently, minimally invasive surgical techniques have freque-

- Received: October 10, 2015 - Revised: December 3, 2015

- Accepted: December 4, 2015

Corresponding Author: Mehmet Sabri Gürbüz, MD

Department of Neurosurgery, Neurosurgery Clinic, Emsey Hospital,

Çamlik mah. Selçuklu cad. No.22 34912, Pendik, Ïstanbul, Turkey

Tel: +902165853700, Fax: +902166460096

E-mail: mehmetsabrigurbuz@gmail.com

®This is an Open Access article distributed under the terms of the Creative

Commons Attribution Non-Commercial License (http://creativecommons.org/ licenses/by-nc/3.0/) which permits unrestricted non-commercial use, distribution, and reproduction in any medium, provided the original work is properly cited. ntly been used for the treatment of spinal pathologies.

The technology of endoscopic spinal surgery has become increasingly popular in recent years due to rapid postoperative recovery and minimal tissue damage ${ }^{4,7,17,18,21)}$. For TCS, although open surgical detethering of the spinal cord is considered to be the gold standard ${ }^{1,9,13,16}$, endoscopic detethering might also be performed as it is a minimally invasive technique with minimal postoperative discomfort. In the English literature, there are only a few cases of TCS operated on with the endoscopic technique. Here we present a case of TCS operated on with a fully endoscopic surgical technique with special emphasis on the advantages of this approach.

\section{CASE REPORT}

\section{Case}

A 19-year-old man was admitted to our neurosurgery clinic with long lasting significant back and bilateral leg pain for which he had undergone several courses of medication and bouts of physical therapy treatment. On examination, he had a lumbosacral hairy dimple and hypoesthesia on the lateral sides of both his thighs. A lumbar magnetic resonance imaging (MRI) scan revealed a thickened, fatty filum with a low-lying conus at the L2-3 level (Fig. 1). The patient's urodynamic parameters were completely normal. Cranial, cervical and thoracic 

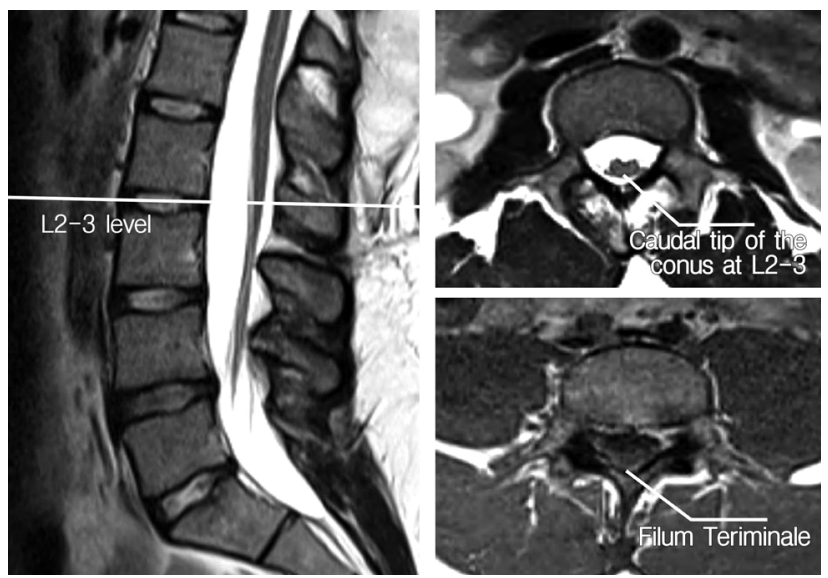

Fig. 1. Preoperative axial and sagittal T2-weighted lumbar MR images of the patient demonstrating a fatty filum and low-lying conus at the L2-3 level.

spinal MRI scans were also taken to rule out any associated abnormality. The patient underwent a L4-5 fully endoscopic detethering and sectioning of the fatty filum under electrophysiological monitoring. The procedure resolved his back and leg pain. His hospitalization lasted for only 2 days because of minimal surgical discomfort. At 2-year follow-up, there was no back or leg pain, and his hypoesthesia had resolved completely.

\section{Surgical Technique}

Similar to the relevant literature ${ }^{10)}$, our patient underwent a fully endoscopic detethering of the spinal cord and sectioning of the filum terminale without the assistance of a loupe or microscope. Under general anesthesia, the patient was placed on the operating table in a prone position and an intraoperative lumbar X-ray was used to localize the L4-5 interlaminar window. A 6.9-mm diameter dilator was inserted through a 5-mm skin incision. A 7.9-mm diameter working cannula was inserted onto the ligamentum flavum, then the dilator was removed and the endoscope was inserted. The operation was maintained under direct endoscopic visualization with continuous high-pressure irrigation with physiological serum. With no need for any manipulation of the lamina only through the interlaminar area the ligamentum flavum was removed with the help of micropunches and the dura was exposed. A 5-mm-long dural incision was made with endoscopic scissors. This incision was enlarged and the fatty filum was identified in the dorsal midline. The lower extremities and the anal sphincter were monitored for electromyographic activity. Along with intraoperative neurophysiological monitoring, the thickened filum terminale was located. Controlled stimulation was performed on the L5 and S1 nerve roots to ensure their correct
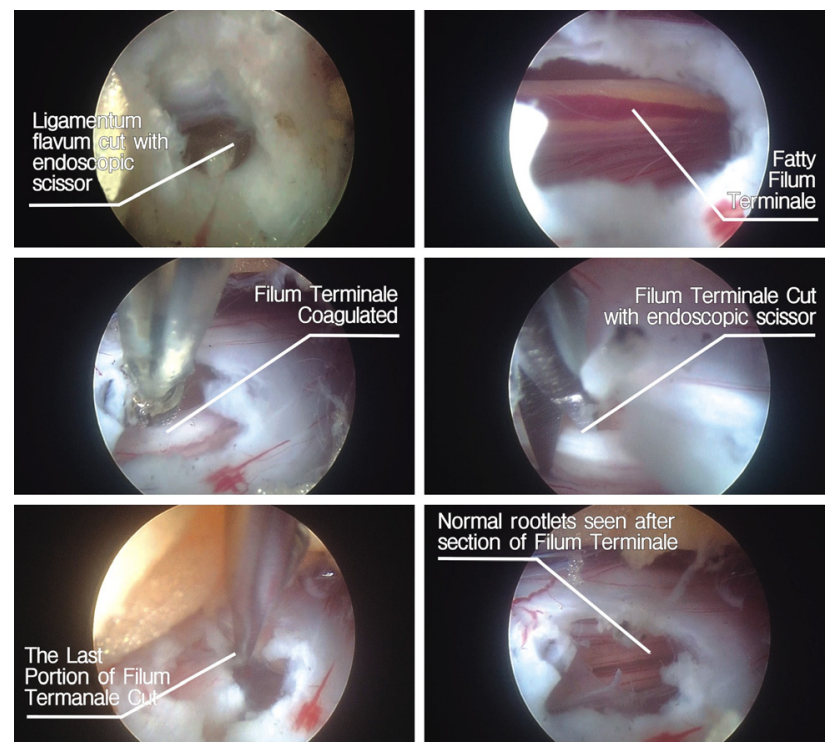

Fig. 2. Endoscopic views revealing the surgical steps including cutting of the ligamentum flavum and exposure of the dura mater, identification of the fatty filum in the dorsal midline, cutting of the fatty filum and the normal rootlets after sectioning of the filum.
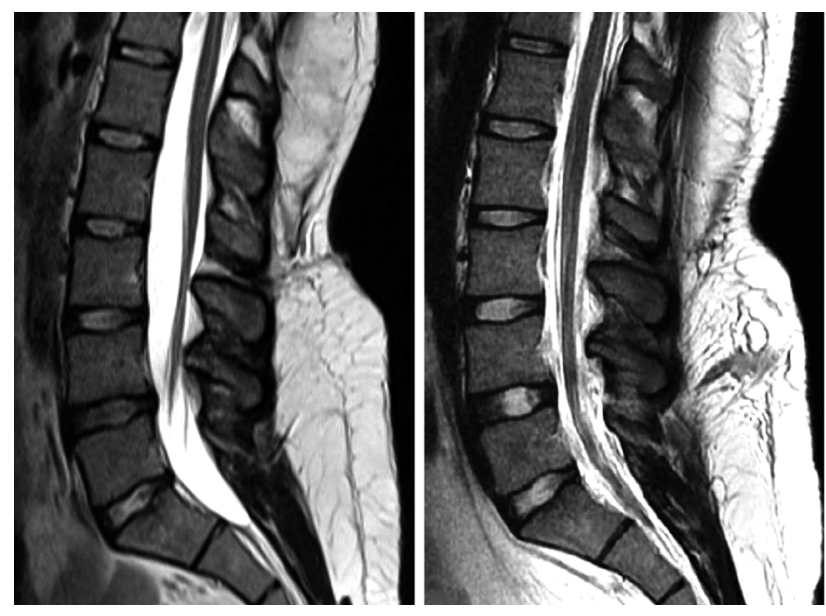

Fig. 3. Preoperative and postoperative T2-weighted sagittal MR images showing relaxation of the nerves in the spinal canal and no CSF leakage.

identification. Once stimulation had failed to produce an electromyographic signal from the sphincter, the filum was coagulated using endoscopic radiofrequency and sectioned with endoscopic scissors (Fig. 2). The dura was closed using inlay Duragen and the skin was closed with only one suture owing to the very small skin incision. The operative time required for this procedure was about $45 \mathrm{~min}$. In comparative preoperative and postoperative $\mathrm{MR}$ images, it was seen that the nerves in the spinal canal were relaxed and there was no cerebrospinal fluid (CSF) leakage (Fig. 3). Two year follow-up MR images 


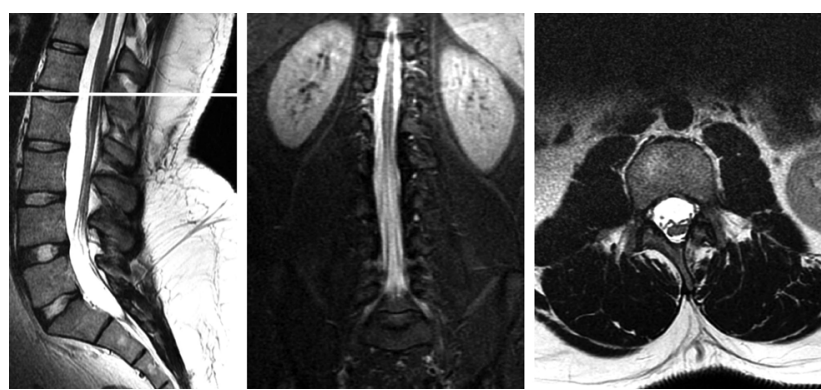

Fig. 4. Two-year-follow-up MR images showing elevation of the conus and no retethering.

showed that conus was elevated and there was no retethering (Fig. 4).

\section{DISCUSSION}

Tethered spinal cord syndrome (TCS) is a neurological disorder caused by tissue attachments that limit the movement of the spinal cord by fixing it within the spinal column. The resultant low-lying and immobile conus medullaris leads to spinal cord tension and abnormal stretching of the spinal cord which results in ischemia ${ }^{35)}$.

TCS may be closely associated with spina bifida, lipomeningomyelocele, split cord malformations, dermal sinus tracts, dermoids, and cystoceles. It may also develop after myelomeningocele operations or following any intradural surgical intervention relevant to the spinal cord ${ }^{25,32)}$. Our patient had a lumbosacral hairy dimple, but no history of previous spinal surgery.

In children, TCS may present with lesions, hairy patches, dimples, or fatty tumors on the lower back, foot and spinal deformities, weakness in the legs, change in or abnormal gait including awkwardness while running or wearing the tips or side of one shoe, lower back pain, scoliosis or urinary irregularities $^{26}$. Adult onset TCS has only been recognized as a definite clinical entity in the past two decades. It is usually diagnosed in childhood, when sensory, motor, bowel, or bladder control issues emerge. This delayed presentation of symptoms relates to the degree of strain on the spinal cord over time. In adults, onset of symptoms typically includes severe leg and/or lower back pain, bilateral muscle weakness and numbness, loss of feeling and movement in the lower extremities, urinary retention, urinary and fecal incontinence ${ }^{3,23,33,34)}$. Our case presented with long lasting significant back and bilateral leg pain and hypoesthesia on the lateral sides of both his thighs.

MRI appears to be the gold standard for diagnosing a tethered cord $^{6}$. TCS, however, is a clinical diagnosis that should be based on neurological and musculoskeletal signs and symp- toms. Imaging features are in general obtained to support rather than make the diagnosis. Aufschnaiter et al..$^{3)}$ emphasized that the conus tip location is not necessarily essential when making the diagnosis of cord tethering. In adults with TCS, the level of the conus tends to be higher than in children ${ }^{20)}$. The level of the conus should therefore not be interpreted in isolation. Tethering can be present with a normally located conus, whereas not every low-lying conus necessarily causes clinical symptoms and requires surgical detethering ${ }^{3,19,32,33)}$. In our case, the diagnosis was made by neurological and musculoskeletal findings and lumbar MRI revealing a fatty filum terminale with low-lying conus at the L2-3 level.

Most authors advocate that surgery should be performed in a timely manner before substantial deficits have evolved ${ }^{20,32,33)}$. Some authors recommend surgery once the diagnosis has been established ${ }^{12)}$, others favor physical therapy as long as the patient responds to it $^{13)}$. Van der Meulen et al. ${ }^{28)}$ reported that early surgery is the most beneficial approach of choice since all of the conservatively followed patients required surgery later and their results were not as good as those who had undergone early surgery. Most of the knowledge with regard to diagnosis, treatment and outcome of TCS is based on experience in children. The benefits and necessity of early surgery in the pediatric group are well-established but the management of adult onset tethered cord syndrome still remains controver$\operatorname{sial}^{23,30)}$. Our case was an adult patient with TCS who had significant symptoms and who had not benefited from several courses of medication and bouts of physical therapy treatment.

Traditionally, open surgical detethering of the spinal cord has yielded good postoperative results ${ }^{1,9,13,16}$. However, some patients develop retethering due to intradural scar formation which generally requires additional surgery ${ }^{24}$. Minimally invasive surgical techniques have been described for the treatment of various spinal pathologies. Endoscopic spinal surgery is a developing field and has had promising surgical results in many areas of spinal surgery. The technology has become increasingly popular in recent years due to rapid postoperative recovery and minimal tissue damage, $e^{4,7,17,21)}$. However, the use of the endoscope for detethering in TCS is a very new technique covering only a few cases. The technique reported and described by $\mathrm{Di}^{10)}$ consists of a 2-cm-long skin incision, hemilaminectomy and use of a retractor with an operative duration of 3 hours. Both techniques (Di's technique and our technique) have the advantages of reduced soft tissue injury, less postoperative pain, minimal blood loss, a smaller incision, and shorter hospitalization. However, unlike Di’s technique, ours is a fully endoscopic technique with a 5-mm-long skin incision, a procedure through an interlaminar window with no need for hemilaminectomy, and with an operative duration of only $45 \mathrm{~min}$. 
The surgical complication rate is generally low in adult patients $^{11)}$. However, the overall complication rate of $9.5 \%$ is within the range of what has previously been reported as $0-12 \%$ for tethered cord surgery ${ }^{5,14,15,22)}$. In our case, no complication was encountered.

The incidence of retethering and the indications for repeat surgery remain controversial. In the pediatric age group, Archibeck et al. ${ }^{2)}$ have suggested that retethering is relatively common with $52 \%$ of patients in their series requiring revision surgery by the age of 5 years. In contrast, the incidence of retethering in adults seems to be significantly lower. Huttmann et al. ${ }^{15)}$ have reported that, over a mean follow-up period of 8 years, only $16 \%$ of patients required repeat detethering surgery. Our patient did not require a repeat detethering procedure during the 2-year follow-up period.

\section{CONCLUSION}

Though larger number of cases are needed to make definite conclusions, our technique of fully endoscopic interlaminar detethering of the spinal cord in TCS has the advantages of reduced soft tissue injury, less postoperative pain, minimal blood loss, a smaller incision, and shorter hospitalization. This minimally invasive surgical technique may also provide a decreased likelihood of scar formation and retethering.

\section{REFERENCES}

1. Akay KM, Ersahin Y, Cakir Y: Tethered cord syndrome in adults. Acta Neurochir (Wien) 142:1111-1115, 2000

2. Archibeck MJ, Smith JT, Carroll KL, Davitt JS, Stevens PM: Surgical release of tethered spinal cord: Survivorship analysis and orthopedic outcome. J Pediatr Orthop 17:773-776, 1997

3. Aufschnaiter K, Fellner F, Wurm G: Surgery in adult onset tethered cord syndrome (ATCS): review of literature on occasion of an exceptional case. Neurosurg Rev 3:371-383, 2008

4. Barami K, Dagnew E: Endoscope-assisted posterior approach for the resection of ventral intradural spinal cord tumors: report of two cases. Minim Invasive Neurosurg 50:370-373, 2007

5. Bowman RM, McLone DG, Grant JA, Tomita T, Ito JA: Spina bifida outcome: a 25-year prospective. Pediatr Neurosurg 34: 114-120, 2001

6. Bulsara KR, Zomorodi AR, Enterline DS, George TM: The value of magnetic resonance imaging in the evaluation of fatty filum terminale. Neurosurgery 4:375-379, 2004

7. Burtscher J, Felber S, Twerdy K, Langmayr JJ: Endoscopeassisted interlaminar removal of an ependymoma of the cauda equina. Minim Invasive Neurosurg 45:41-44, 2002

8. Cartwright C: Primary tethered cord syndrome: diagnosis and treatment of an insidious defect. J Neurosci Nurs 32:210-215, 2000
9. Cornette L, Verpoorten C, Lagae L, van Calenbergh F, Plets $\mathrm{C}$, Vereecken R, et al: Tethered cord syndrome in occult spinal dysraphism: timing and outcome of surgical release. Neurology 50:1761-1765, 1998

10. Di X: Endoscopic spinal tethered cord release: operative technique. Childs Nerv Syst 25:577-581, 2009

11. Garg K, Tandon V, Kumar R, Sharma BS, Mahapatra AK: Management of adult tethered cord syndrome: our experience and review of literature. Neurol India 62:137-143, 2014

12. Gupta SK, Khosla VK, Sharma BS, Mathuriya SN, Pathak A, Tewari MK: Tethered cord syndrome in adults. Surg Neurol 52:362-369, 1999

13. Haro H, Komori H, Okawa A, Kawabata S, Shinomiya K: Longterm outcomes of surgical treatment for tethered cord syndrome. J Spinal Disord Tech 17:16-20, 2004

14. Herman JM, McLone DG, Storrs BB, Dauser RC: Analysis of 153 patients with myelomeningocele or spinal lipoma reoperated upon for a tethered cord. Presentation, management and outcome. Pediatr Neurosurg 19:243-249, 1993

15. Huttmann S, Krauss J, Collmann H, Sörensen N, Roosen K: Surgical management of tethered spinal cord in adults: report of 54 cases. J Neurosurg 95:173-178, 2001

16. Iskandar BJ, Fulmer BB, Hadley MN, Oakes WJ: Congenital tethered spinal cord syndrome in adults. J Neurosurg 88:958961, 1998

17. Kalavakonda C, Sekhar LN, Ramachandran P, Hechl P: Endoscope-assisted microsurgery for intracranial aneurysms. Neurosurgery 51:1119-1126, 2002

18. Kang JK, Lee KS, Jeun SS, Lee IW, Kim MC: Role of surgery for maintaining urological function and prevention of retethering in the treatment of lipomeningomyelocele: experience recorded in 75 lipomeningomyelocele patients. Childs Nerv Syst 19:23-29, 2003

19. Kirollos RW, Van Hille PT: Evaluation of surgery for the tethered cord syndrome using a new grading system. Br J Neurosurg 10:253-260, 1996

20. Klekamp J, Raimondi AJ, Samii M: Occult dysraphism in adulthood: clinical course and management. Childs Nerv Syst 10: 312-320, 1994

21. Knight MT, Vajda A, Jakab GV, Awan S: Endoscopic laser foraminoplasty on the lumbar spine - early experience. Minim Invasive Neurosurg 41:5-9, 1998

22. Lad SP, Patil CG, Ho C, Edwards MS, Boakye M: Tethered cord syndrome: nationwide inpatient complications and outcomes. Neurosurg Focus 23:1-5, 2007

23. Lapsiwala SB, Iskandar BJ: The tethered cord syndrome in adults with spina bifida occulta. Neurol Res 26:735-740, 2004

24. Meyrat BJ, Tercier S, Lutz N, Rilliet B, Forcada-Guex M, Vernet O: Introduction of a urodynamic score to detect preand postoperative neurological deficits in children with a primary tethered cord. Childs Nerv Syst 19:716-721, 2003

25. Ohe N, Futamura A, Kawada R, Minatsu H, Kohmura H, Hayashi K, et al: Secondary tethered cord syndrome in spinal dysraphism. Childs Nerv Syst 16:457-461, 2000

26. Phuong LK, Schoeberl KA, Raffel C: Natural history of tethered cord in patients with meningomyelocele. Neurosurgery 50:989993, 2002

27. Tubbs RS, Oakes WJ: Tethered cord syndrome in adult in 
Schmidek \& Sweet (eds): Operative Neurosurgical Techniques. Indications, Methods and Results, ed 5. Philadelphia: W.B. Saunders Elsevier, Vol 2, 2006

28. van der Meulen WD, Hoving EW, Staal-Schreinemacher A, Begeer JH: Analysis of different treatment modalities of tethered cord syndrome. Childs Nerv Syst 18:513-517, 2002

29. Vernet O, Farmer JP, Houle AM, Montes JL: Impact of urodynamic studies on the surgical management of spinal cord tethering. J Neurosurg 85:555-559, 1996

30. Vogel S, Neumaerker K, Klepel K: The optimal time for operative treatment of the tethered cord syndrome. Adv Neurosurg 18:155-157, 1990

31. Wehby MC, O’Hollaren PS, Abtin K, Hume JL, Richards BJ:
Occult tight filum terminale syndrome: results of surgical untethering. Pediatr Neurosurg 40:51-58, 2004

32. Yamada S, Knerium DS, Mandybur GM, Schultz RL, Yamada BS: Pathophysiology of tethered cord syndrome and other complex factors. Neurol Res 26:722-726, 2004

33. Yamada S, Lonser RR: Adult tethered cord syndrome. J Spinal Disord 13:319-323, 2000

34. Yamada S, Siddiqi J, Won DJ, Kido DK, Hadden A, Spitalieri J, et al: Symptomatic protocols for adult tethered cord syndrome. Neurol Res 26:741-744, 2004

35. Yamada S, Zinke DE, Sanders D: Pathophysiology of "tethered cord syndrome”. J Neurosurg 54:494-503, 1981 